\title{
Surgical resection of spinal teratomas, when the enemy of good surgical outcome can be trying for better?
}

Teratomas are tumors that contain components from three (or less commonly two) primitive germ cells namely ectoderm-endoderm and mesoderm. The tumor may contain well-differentiated or immature components and can be malignant.

In spite of rarity of tumors in children, teratomas are among the most common type encountered, usually in the sacral area, more common in females, and less common in adults. ${ }^{[1]}$ Report of the society of paediatric pathology in the UK identified teratoma as the most common neonatal tumor $(23.5 \%))^{[2]}$ The occurrence of teratomas in the spinal column is none the less rare. A comprehensive review identified 58 cases with a mention of only two intraspinal teratomas in over 1300 cases. ${ }^{[3]}$ The most common location of teratomas in the spinal column is the thoracolumbar region and rarely in the cervical spine. ${ }^{[4]}$ The presence of intramedullary teratomas has been reported in about a dozen cases. In this case report, Oktay et al. ${ }^{[5]}$ presented interesting findings in a 12-year-old patient and describe the clinical, surgical, and pathological findings. They reported $95 \%$ of tumor removal with the remaining $5 \%$ left in place because of adherence to the neural structures. This adds to the handful of previous reports which is interesting by itself. Furthermore, the case report raises an interesting surgical dilemma of full resection of a potentially benign lesion, at the potential cost of neurological loss, versus an incomplete removal, with good neurological outcome. The previous series had reported that full resection was only possible in just over $60 \%$ of cases. The judicial use of electrophysiological monitoring could assist with the finely tuned decision dilemma, to attempt a full resection with least neurological consequences. The previously mentioned types of tumor and potential malignancy also play a role in the decision making. The mature teratomas, which are most common (90\%), are less likely to reoccur than immature or malignant ones and in these cases, the threshold for a more complete resection has to be understandably lower. The use of intraoperative sampling is of some potential benefit to make this intraoperative decision. Unexpectedly, there appears to be little correlation between the extent of tumor resection, and recurrence whereas, immature tumors appears to reoccur more frequently. ${ }^{[3]}$ In conclusion, each rare case of intramedullary teratoma is worth careful scrutiny to determine if full resection is possible with least neurological cost and to bail out if the latter becomes threatened. In short, to resist the temptation of trying for better, at a cost of a good surgical outcome.

Babak Arvin

Department of Neurosurgery, Queens Hospital, Rom Valley Way, Romford Essex RM7 OAG, UK

Address for correspondence: Dr. Arvin Babak

Department of Neurosurgery, Queens Hospital, Rom Valley Way, Romford, Essex RM7 OAG, UK E-mail: arvin.babak@bhrhospitals.nhs.uk

\section{References}

1. Schropp KP, Lobe TE, Rao B, Mutabagani K, Kay GA, Gilchrist BF, et al. Sacrococcygeal teratoma: The experience of four decades. J Pediatr Surg 1992;27:1075-8.

2. Barson AJ. Congenital neoplasia. The society's experience. Arch Dis Child 1978;53:436.

3. Allsopp G, Sgouros S, Barber P, Walsh AR. Spinal teratoma: Is there a place for adjuvant treatment? Two cases and a review of the literature. Br J Neurosurg 2000;14:482-8.

4. Arvin B, Pohl U, David K. Intramedullary cervical teratoma in an adult. Spine J 2009;9:e14-8.

5. Oktay K, Cetinalp NE, Ozsoy KM, Olguner SK, Sarac ME, Vural SB. Intramedullary mature teratoma of the conus medullaris. J Neurosci Rural Pract 2016;7:305-7.

This is an open access article distributed under the terms of the Creative Commons Attribution-NonCommercial-ShareAlike 3.0 License, which allows others to remix, tweak, and build upon the work non-commercially, as long as the author is credited and the new creations are licensed under the identical terms.

\begin{tabular}{|l|l|}
\hline \multicolumn{2}{|c|}{ Access this article online } \\
\hline Quick Response Code: & Website: \\
\hline & www.ruralneuropractice.com \\
\hline & \\
\hline
\end{tabular}

How to cite this article: Arvin B. Surgical resection of spinal teratomas, when the enemy of good surgical outcome can be trying for better? J Neurosci Rural Pract 2016;7:199. 